\title{
ANÁLISE DO PERFIL DOS ALUNOS EGRESSOS DO CURSO DE ENGENHARIA CIVIL DA UNIVERSIDADE FEDERAL DA PARAÍBA ENTRE OS ANOS DE 2009 E 2018
}

Paulo Fernando Dutra-pf.oliveira@outlook.com

Universidade Federal da Paraíba

Campus Universitário I, Centro de Tecnologia, Departamento de Engenharia Civil e Ambiental CEP: 58.051-900. João Pessoa-PB

Pablo Brilhante de Sousa - pablo.brilhante@academico.ufpb.br

Universidade Federal da Paraíba

Campus Universitário I, Centro de Tecnologia, Departamento de Engenharia Civil e Ambiental CEP: 58.051-900. João Pessoa-PB

Resumo: O curso de Engenharia Civil da Universidade Federal da Paraíba formou, nos últimos 10 anos, mais de 650 alunos. Este artigo tem como objetivo fazer a análise do perfil desses profissionais com o levantamento de suas características socioeconômicas como: escolaridade, renda, sexo, situação e inserção profissional. Os dados foram levantados por meio da aplicação de um formulário online, os participantes foram classificados a partir de suas respostas e agrupados de acordo com suas características comuns. Os resultados mostram a configuração de um cenário preocupante para os Engenheiros Civis formados nos últimos anos, principalmente em questões como inserção e satisfação profissional.

Palavras-chave: Avaliação. Egressos. Emprego. Engenharia Civil. 


\section{INTRODUÇÃ̃O}

As mudanças trazidas pela globalização no modo como as relações internacionais se deram em diferentes planos e juntamente às evoluções no processo de produção experimentadas pela indústria, marcadas pelo dinamismo estratégico, fazem surgir a primazia por profissionais que mobilizam um conjunto de recursos cognitivos para solucionar diferentes situações de maneira eficaz e pertinente. (LIMA E ANDRIOLA, 2018).

Tendo em vista que o egresso é o produto final das Instituições de Ensino Superior (IES), é justificado o emprego de esforços para analisar sua empregabilidade, fazendo disso uma consequente avaliação da universidade. Além disso, há uma troca de informações e colaboração entre ambas as partes, onde egressos colaboram com a construção de políticas de empregabilidade das universidades e estas se municiam no auxílio ao estudante na formação para o mercado de trabalho (ALBERTE, 2018).

A partir da publicação das novas Diretrizes Curriculares Nacionais do Curso de Graduação em Engenharia (DCNs de Engenharia) em abril de 2019, que consideram a necessidade em se atualizar a formação desses profissionais no País, com o objetivo de atender as futuras demandas quantitativas e qualitativas de engenheiros, os cursos de graduação receberam o desafio da implementação de mudanças como a formação por competências, flexibilização no currículo, foco na formação prática e interdisciplinaridade, todas aliadas à necessidade de conexão com as demandas do mercado.

Com isto, e somando-se a necessidade de atualizações periódicas dos Projetos Pedagógicos dos Cursos (PPCs), ratificadas com a publicação das novas DCNs, este trabalho possui como objetivo geral o levantamento do perfil do egresso do curso de Engenharia Civil da Universidade Federal da Paraíba (UFPB), a partir de suas características socioeconômicas e sua inserção no mercado de trabalho.

\section{METODOLOGIA}

De acordo com GIL (2018), um questionário é um conjunto de questões submetidas a pessoas com o objetivo de se obter informações gerais sobre diferentes aspectos de uma população, e que juntas compõem uma técnica de investigação. Sendo propostos, na maioria das vezes, por escrito aos participantes, são designados como "auto aplicados", caso do questionário elaborado para este trabalho.

$\mathrm{O}$ questionário foi produzindo contendo um total de 44 perguntas. $\mathrm{O}$ instrumento foi enviado a 599 alunos formados entre os anos de 2009 e 2018. O formulário foi enviado a todos os egressos do curso no período citado, constantes nos registros da IES. A amostra mínima necessária para conferir ao estudo um índice de confiança de 95\%, foi calculada em 165 participantes, com uma margem de erro de $6,5 \%$.

$\mathrm{O}$ formulário foi elaborado em meio digital utilizando a ferramenta Google Forms e enviado aos alunos via $e$-mail, a partir dos endereços eletrônicos presentes na base de dados da IES. As informações coletadas foram transferidas, tratadas e analisadas utilizando a ferramenta Microsoft Excel.

O questionário foi dividido em 7 seções, cada qual com diferentes objetivos, de modo a identificar e direcionar o participante de modo que não fosse necessário responder a perguntas que não fossem adequadas ao seu perfil socioeconômico ou sua colocação no mercado de trabalho. 
A primeira seção, de caráter introdutório, apresentou ao respondente o intuito do instrumento, que é o de coletar dados de alunos egressos do curso para os últimos 10 anos e que, por meio da avaliação desses dados, seria feita uma análise socioeconômica e de inserção profissional.

A seção seguinte trouxe perguntas específicas a respeito de idade, gênero, grupo étnico com o qual o indivíduo se identifica, escolaridade e tipo de instituição de ensino (se pública ou privada) em que estudou a maior parte do ensino fundamental e médio. Nesta seção também foram inseridas algumas perguntas introdutórias na avaliação acadêmica e profissional, tais como: ano de início e de conclusão da graduação em Engenharia Civil, se possui registro no Conselho Regional de Engenharia e Agronomia (CREA), se o respondente sentia-se preparado para atuar no mercado de trabalho ao concluir o curso, como se declara em relação a satisfação profissional e qual sua renda mensal.

A Seção 2 é encerrada com a pergunta "Você está empregado(a) atualmente?", oferecendo ao respondente as opções "sim" ou "não". A partir daí, os respondentes são divididos em dois grupos denominados "Engenheiros(as) empregados(as)" e "Engenheiros(as) em desemprego". Ressalta-se a diferença na nomenclatura dos grupos que, no segundo, trouxe o termo "em desemprego", com o intuito de considerar tal situação em que o(a) profissional se encontra como temporária, e não uma característica sua, tentando-se evitar, assim, algum tipo de constrangimento.

Dentre o grupo de respondentes empregados, a Seção 3 perguntou qual a natureza de sua ocupação principal, se trabalha em empresa no setor privado, se é profissional liberal ou autônomo, se é proprietário de empresa ou firma individual, ou é funcionário em uma das esferas do setor público. Também foram colocadas as opções caso o respondente tenha seguido a carreira acadêmica, militar ou esteja aposentado.

Avaliando a inserção profissional do participante, a seção também apresentou questões sobre a localidade de sua atividade, há quanto tempo está em seu vínculo profissional atual, se o primeiro emprego após formado foi em Engenharia Civil e, em quanto tempo, conseguiu o emprego na área.

Aqueles que responderam negativamente à questão apresentada ao final da Seção 2 ("Você está empregado atualmente?") foram direcionados para a Seção 4, na qual são apresentadas questões exploratórias sobre a atuação do profissional enquanto engenheiro(a) civil. Deseja-se saber há quanto tempo está fora de atividade, e quais os motivos que o trouxeram a sua situação profissional atual. Duas perguntas são apresentadas, ao final da seção, que têm o objetivo de avaliar o quanto o respondente acredita que qualificação recebida durante a graduação influencia em sua situação atual e se há uma pretensão em mudar de área de atuação.

Tanto os participantes empregados, quanto os desempregados, são encaminhados para a Seção 5, que separará os grupos entre aqueles que não atuam em Engenharia Civil e aqueles que atuam. As áreas de atuação apresentadas no questionário são aquelas presentes no Plano Político Pedagógico do curso em análise, sendo: Construção Civil, Estruturas e Fundações, Transportes, Saneamento, Recursos Hídricos e Geotecnia. Também foram adicionadas as áreas de Engenharia Diagnóstica e Planejamento e Gestão.

A Seção 6 é apresentada aos profissionais que não atuam em Engenharia Civil e coleta informações sobre qual a área em que estão inseridos, bem como há quanto tempo estão nela. Busca-se saber quais os motivos levaram o respondente a mudar de área, oferecendo opções que vão desde expectativas desencontradas, passando por interesse em outras áreas, percepção de que o mercado está em declínio, mudanças de prioridades, perseguir um sonho, rotina estressante, buscar novos desafios, até uma possível decepção com o curso. O formulário é encerrado para o participante desse grupo ao final da seção. 
A última seção do questionário é destinada aos egressos do curso que atuam em alguma área da Engenharia Civil. Nessa etapa, os participantes avaliaram a sua inserção no mercado de trabalho, bem como o quanto sua formação influencia na sua colocação profissional atual.

Com relação ao mercado de trabalho, a seção traz perguntas que buscam identificar qual a percepção do respondente quanto a relação entre universidade e mercado de trabalho, se, há uma interação entre ambos, se o participante, enquanto aluno, esteve em contato com práticas ou tecnologias que hoje utiliza em sua área de atuação e se há uma correspondência entre o conteúdo aprendido e o que é praticado na atividade profissional.

A seção encerra-se com perguntas que questionam ao respondente como ele se sentia enquanto participante na experiência de ensino-aprendizagem, trazendo a opção de se descrever enquanto um agente passivo ou ativo em sala de aula. A Figura 1 sintetiza as seções do questionário aplicado.

Figura 1 - Fluxograma das seções do questionário aplicado

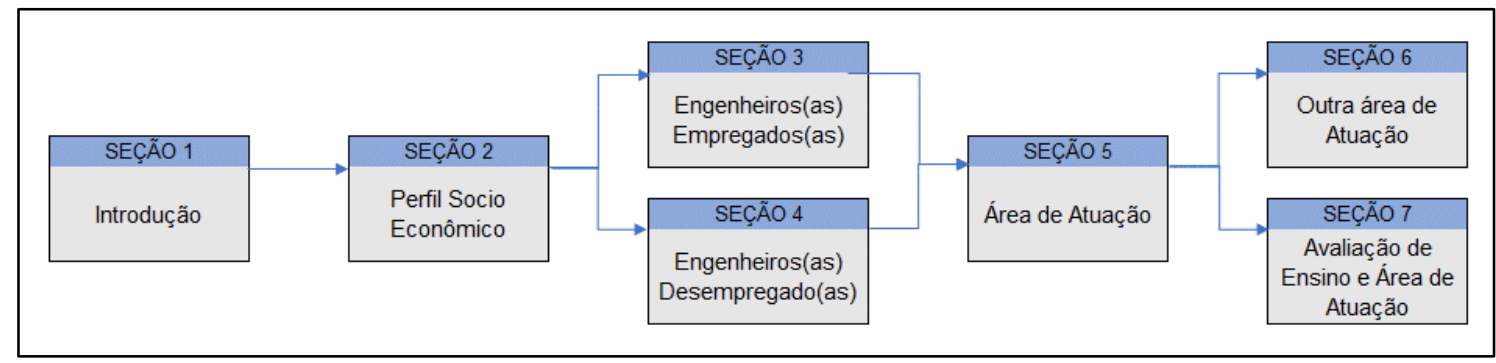

Fonte: Os autores (2020)

\section{ANÁLISE E INTERPRETAÇÃO DOS DADOS}

\section{Os engenheiros civis}

Com $30 \%$ de taxa de resposta aos e-mails enviados, totalizando 181 egressos, atendendo ao número mínimo de respostas necessárias, foi possível montar a análise objetivo deste trabalho.

Os profissionais formados pelas turmas pesquisadas são majoritariamente do sexo masculino, representando $61 \%$ dos egressos, enquanto as mulheres representam $39 \%$ da população. Quando perguntados com qual grupo étnico eles se identificam, pouco mais da metade, 53,5\%, autodeclaram-se "brancos", enquanto 41,3\% identificam-se como "pardos" e apenas $4,7 \%$, "negros".

\section{Escolaridade}

Apenas 28,5\% dos alunos estudaram a maior parte do tempo em instituições de ensino público durante o ensino fundamental e médio. Após formados, 40,1\% dos egressos continuam apenas com a graduação como seu nível de escolaridade, 20,3\% possuem pós-graduação, 11,6\% especialização, $22,1 \%$ possuem mestrado e apenas $5,8 \%$, doutorado.

\section{Remuneração mensal média}

A salário médio dos profissionais participantes dessa pesquisa é de $\mathrm{R} \$ 4.575,09$. Com variações que vão de $\mathrm{R} \$ 500,00$ a $\mathrm{R} \$ 25.000,00$. O salário médio dos homens é de $\mathrm{R} \$ 4.890,41$, enquanto o das mulheres é de $\mathrm{R} \$ 4.803,56$, uma diferença de $20 \%$.

Quando analisados os salários de acordo com o grau de escolaridade dos profissionais, aqueles que possuem apenas a graduação, têm um salário médio de $\mathrm{R} \$ 3.100,00$, enquanto os pós-graduados e mestres, $\mathrm{R} \$ 5.302,31$ e $\mathrm{R} \$ 5.115,65$, respectivamente. Os maiores salários 
registrados pertencem ao grupo dos profissionais que possuem doutorado, atingindo uma média de $\mathrm{R} \$ 8.774,00$ mensal. A Figura 2 mostra a relação entre escolaridade e renda mensal.

Figura 2 - Relação entre escolaridade e renda mensal

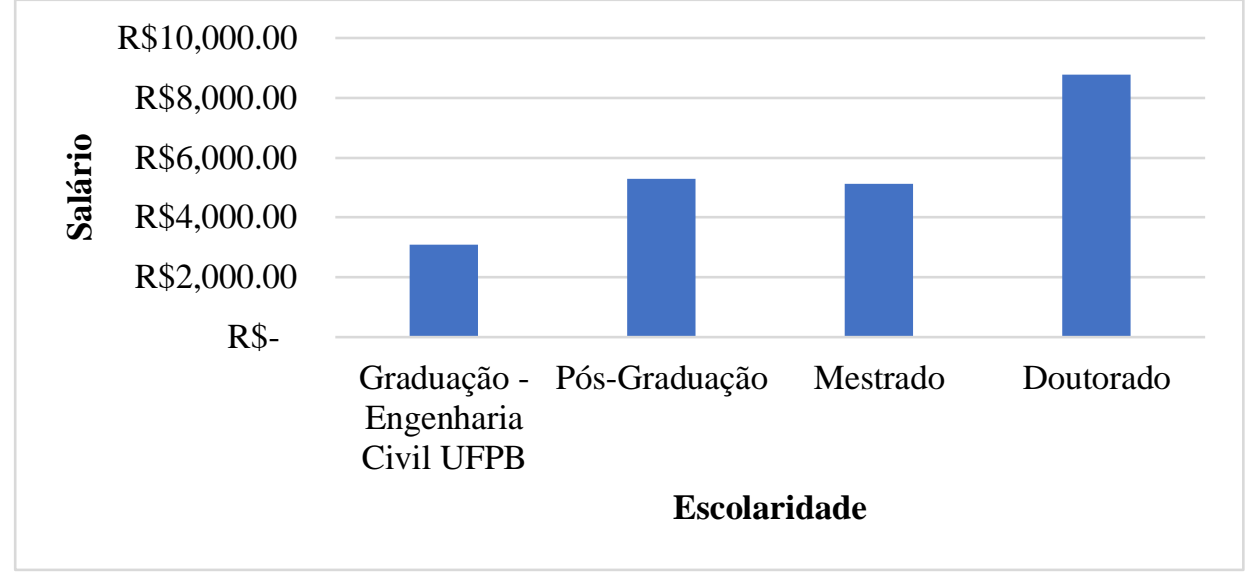

Fonte: Os autores (2020)

A Figura apresenta a evolução da renda média mensal e os anos de experiência profissional dos participantes. Conforme observado, a renda mensal cresce à medida em que aumenta o tempo de experiência profissional. Os resultados sugerem uma renda média mensal de $\mathrm{R} \$ 1.645,75$ para o recém-formado, sendo acrescido, em média, o valor de $\mathrm{R} \$ 810,43$ para cada ano adicional de trabalho.

Figura 3 - Evolução da Renda Mensal com a Experiência Profissional

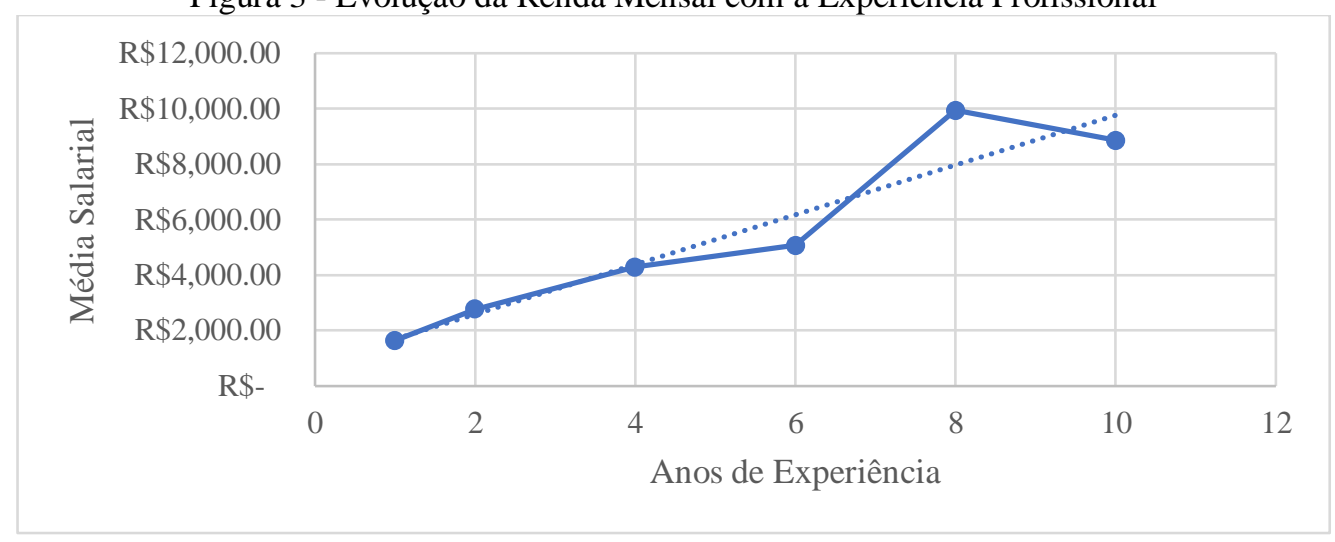

\section{O exercício profissional}

Fonte: Os autores (2020)

\section{Registro no CREA}

A primeira questão, a que os pesquisados foram submetidos no questionário a respeito do seu exercício profissional, foi a de possuírem registro no Conselho Regional de Engenharia e Agronomia (CREA). Os dados apontam que 77\% deles possuem registro no conselho, enquanto $23 \%$ não possuem.

Quando analisado o número de registros no conselho por ano de graduação, percebe-se um aumento na quantidade de profissionais que não estão associados ao órgão, conforme pode ser conferido na Figura 4, em que o número de egressos sem registro chega a $38 \%$ nas turmas dos últimos dois anos. 
(C) COBENCE 2020

"Os desafios para formar hoje o engenheiro do amanhã"
$\mathrm{Ol} \mathrm{a} \mathrm{O3}$ de dezembro Evento On-line

Figura 4 - Profissionais não registrados no CREA por grupos de anos

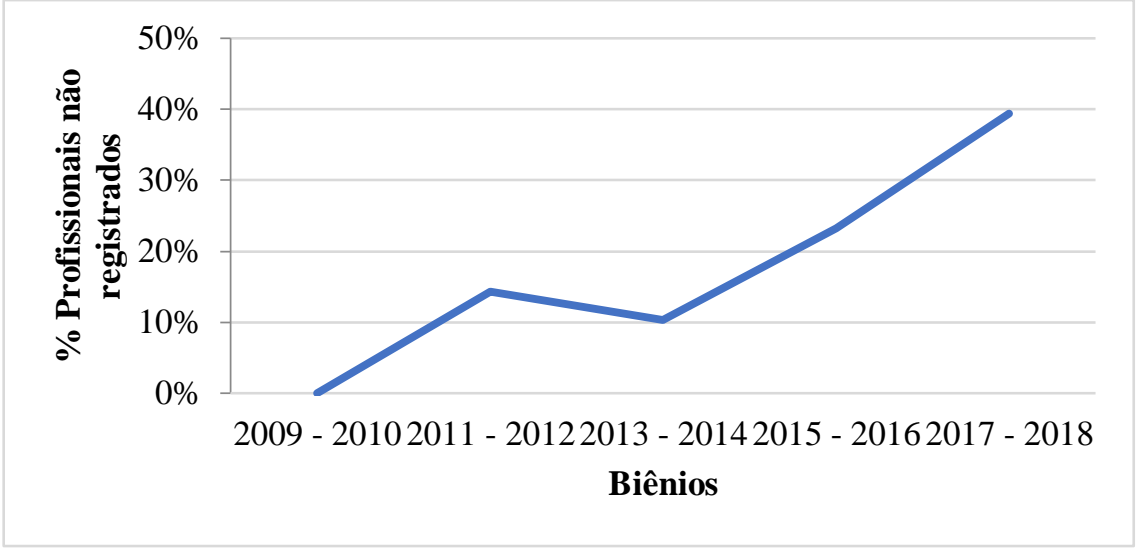

Fonte: Os autores (2020)

\section{Preparação para atuar no mercado de trabalho}

Os participantes foram questionados quanto ao sentimento de preparo para atuação no mercado de trabalho quando concluíram a graduação. Dentre os pesquisados, os que não se sentiam preparados, totalizaram $58 \%$ dos participantes, contra $42 \%$ que responderam afirmativamente.

\section{Emprego, desemprego e satisfação profissional}

O número de alunos egressos do curso de Engenharia Civil da UFPB, que não estão empregados, é de $36 \%$ do total de participantes. Apesar de $64 \%$ dos pesquisados estarem empregados, uma segunda análise foi feita para investigar como está a situação empregatícia dos participantes de acordo com o ano em que concluíram a graduação. Vale ressaltar que a porcentagem de desempregados, entre os recém-graduados, é de $56 \%$ dos egressos entre os anos de 2017 e 2018, conforme mostra a Figura 5.

Quando perguntados a respeito de sua satisfação profissional, 52\% dos participantes responderam estarem satisfeitos atualmente, enquanto $48 \%$ afirmaram estarem insatisfeitos ou indiferentes com a profissão. O nível de satisfação entre os profissionais formados nos últimos anos é consideravelmente menor que o daqueles formados nos anos de 2009 à 2015, conforme apresentado na Figura 6, atingindo o valor mínimo de $25 \%$ de satisfação entre os egressos do ano de 2018.

Figura 5 - Porcentagem de alunos desempregados por ano de conclusão

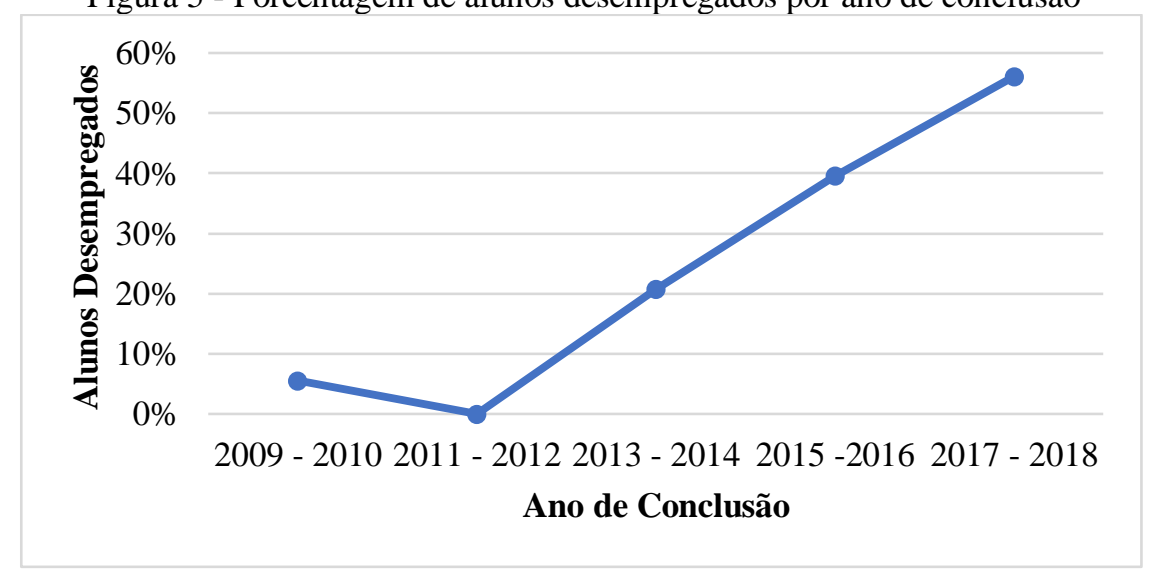

Fonte: Os autores (2020) 
Figura 6 - Egressos satisfeitos com sua situação profissional por ano de graduação

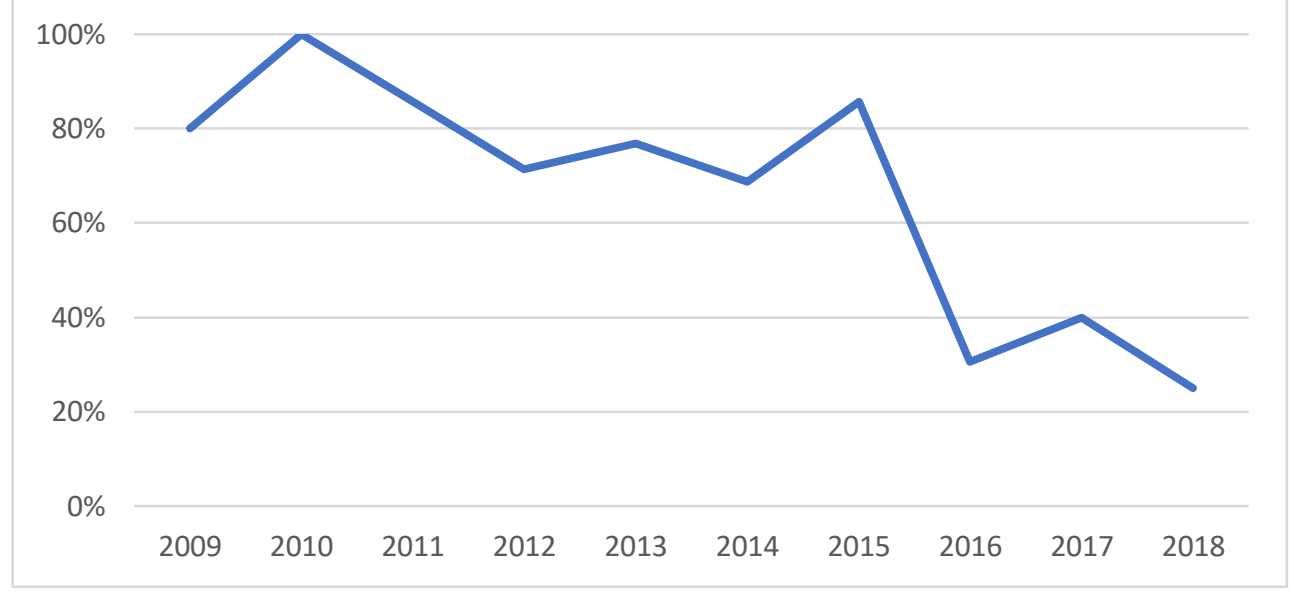

Fonte: Os autores (2020)

\section{Natureza da ocupação}

Entre os participantes que declararam estar em atividade profissional, apenas 5,3\% deles são autônomos. Os empresários totalizam 18,6\% dos egressos. Há uma significativa representatividade entre os que seguiram carreira acadêmica, sendo 10,6\% da amostra. Houve resposta de alguns egressos que seguiram a carreira militar, somando $0,9 \%$.

Um grupo composto por 64,6\% dos respondentes, é empregado em empresas no setor público ou privado. Este último é responsável por empregar 30,1\% dos egressos em Engenharia Civil, enquanto o primeiro detém $34,5 \%$ dos postos de trabalho dos formados. A Figura 7 resume a porcentagem de egressos e as respectivas atividades profissionais.

Figura 7 - Porcentagem de egressos e atividade profissional principal

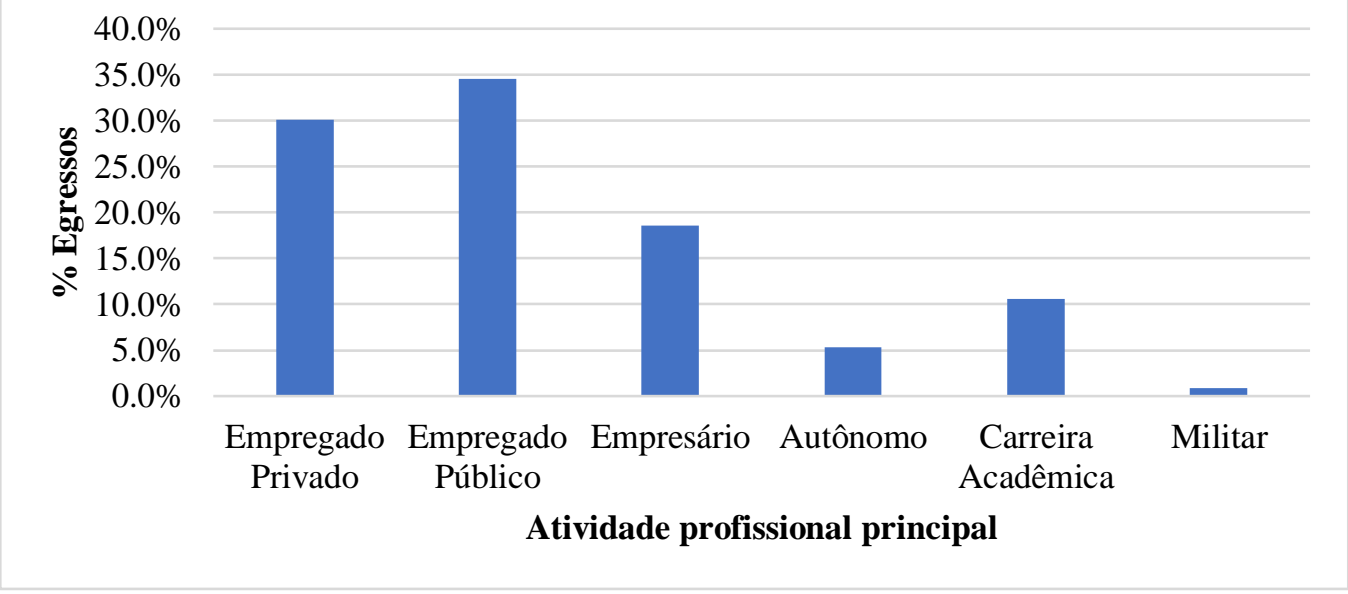

Fonte: Os autores (2020)

\section{Salário e natureza de ocupação}

Seguindo a tendência como setores que mais empregam os pesquisados, os empregos público e privado lideram as margens salariais dos engenheiros, com médias de $\mathrm{R} \$ 6.647,91$ e R \$7.293,29, respectivamente. Empresários, autônomos e militares mantêm-se equiparados financeiramente, com salários variando em torno dos $\mathrm{R} \$ 5.000,00$ mensais. Aqueles que optaram pela carreira acadêmica têm vencimentos na ordem dos $\mathrm{R} \$ 6.000,00$. A Figura 8 demonstra a média salarial por atividade profissional principal. 
Figura 8 - Média salarial por atividade profissional principal

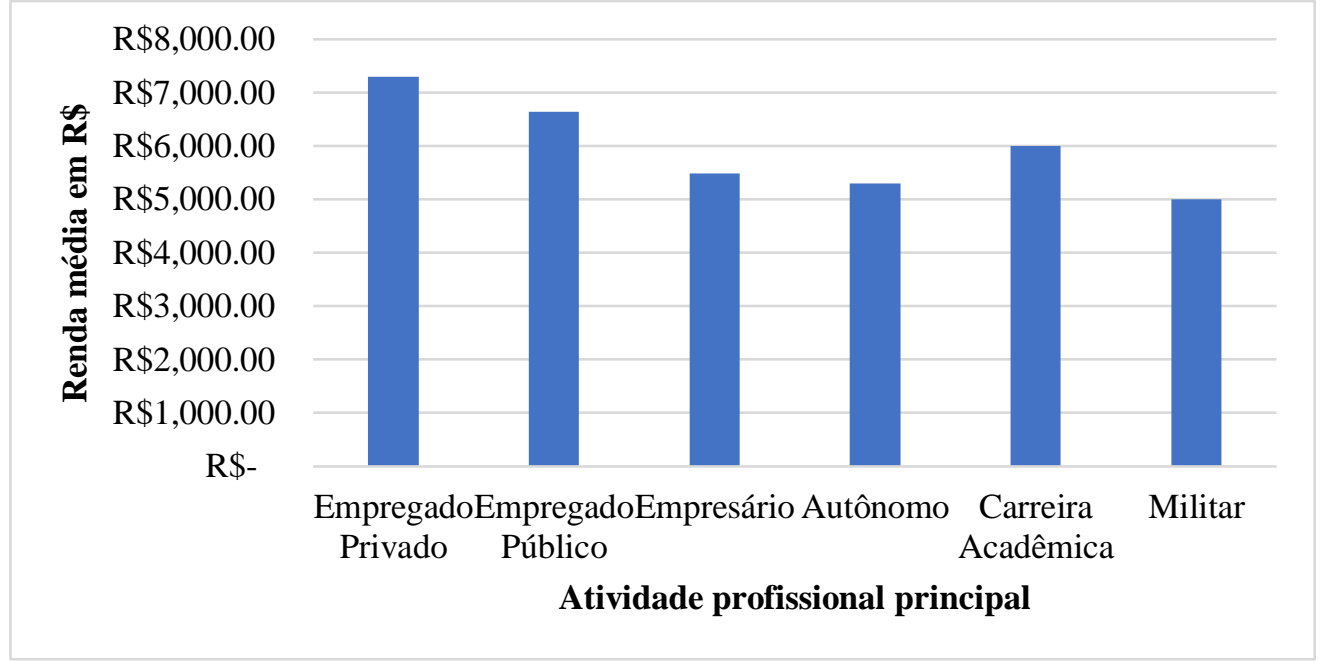

Fonte: Os autores (2020)

\section{Área de atuação}

A Figura 9 apresenta a distribuição dos egressos, em suas áreas de atuação, conforme as áreas das disciplinas oferecidas na grade curricular do curso da UFPB. São elas: Construção Civil, Estradas e Transportes, Estruturas e Fundações, Geotecnia, Planejamento e Gestão, Recursos Hídricos e Saneamento.

A Construção Civil destaca-se como a área de maior atuação, onde $48 \%$ dos egressos trabalham atualmente. Em segundo lugar está a não atuação na Engenharia Civil, com $21 \%$ dos participantes, superior a quantidade de egressos que atuam em outras áreas da Engenharia.

Figura 9 - Porcentagem de egressos e área de atuação

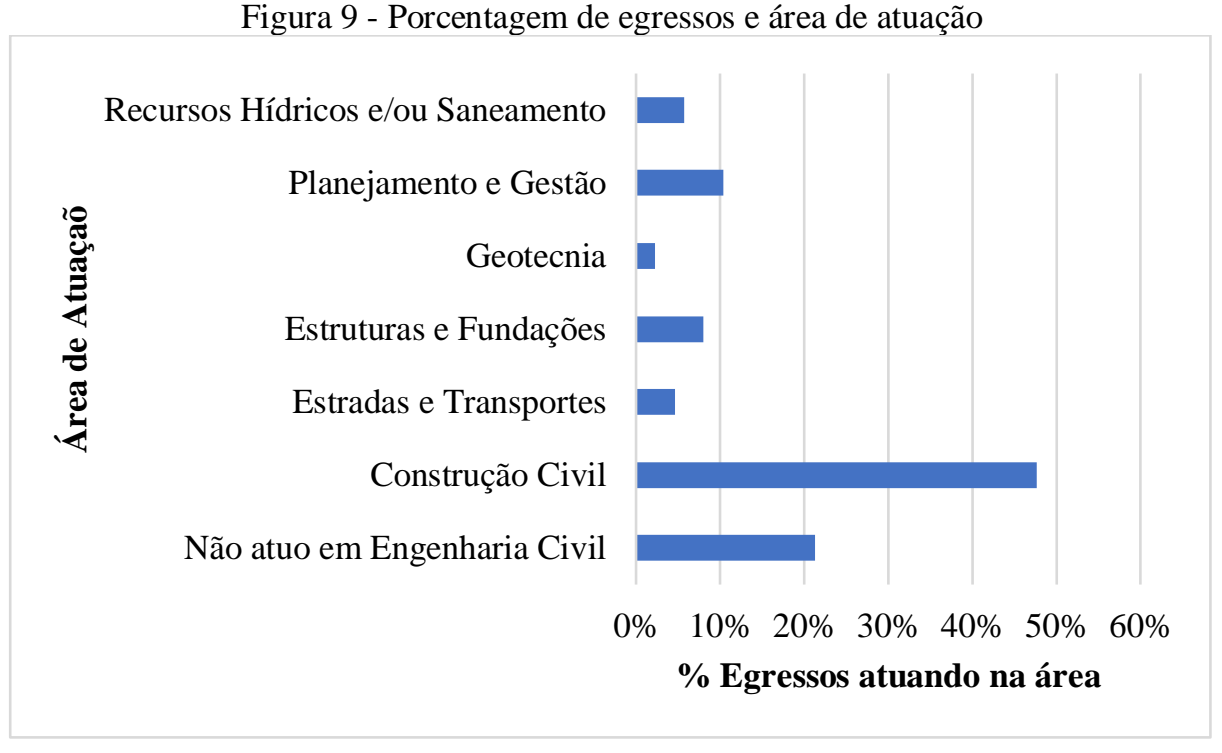

Fonte: Os autores (2020)

\section{Salários e área de atuação}

A distribuição salarial segue uma classificação diferente daquela apresentada na escolha da área de atuação dos profissionais, conforme indicado na Figura 10 a seguir. Um resultado observado foi que as áreas, com menor número de profissionais atuantes, não significam uma média salarial menor. 
Como pode ser observado, a Construção Civil, apesar de ser a área de maior atuação dentre os profissionais, oferece um salário médio de $\mathrm{R} \$ 6.520,89$, menor que o de áreas menos procuradas, a exemplo de Estradas e Transportes, com salário médio de $\mathrm{R} \$ 6.976,00$. Os profissionais das áreas de Estruturas e Fundações e Recursos Hídricos e Saneamento possuem salários de $\mathrm{R} \$ 5.837,50$ e $\mathrm{R} \$ 5.670,00$, respectivamente. Destaque especial deve ser dado à área de Planejamento e Gestão, com apenas $10 \%$ dos profissionais, porém com o maior salário registrado, de $\mathrm{R} \$ 8.374,84$. Entre aqueles que não atuam em Engenharia Civil, o salário médio apresentado é de $\mathrm{R} \$ 4.636,57$.

Figura 10 - Participação profissional e salário médio por área de atuação

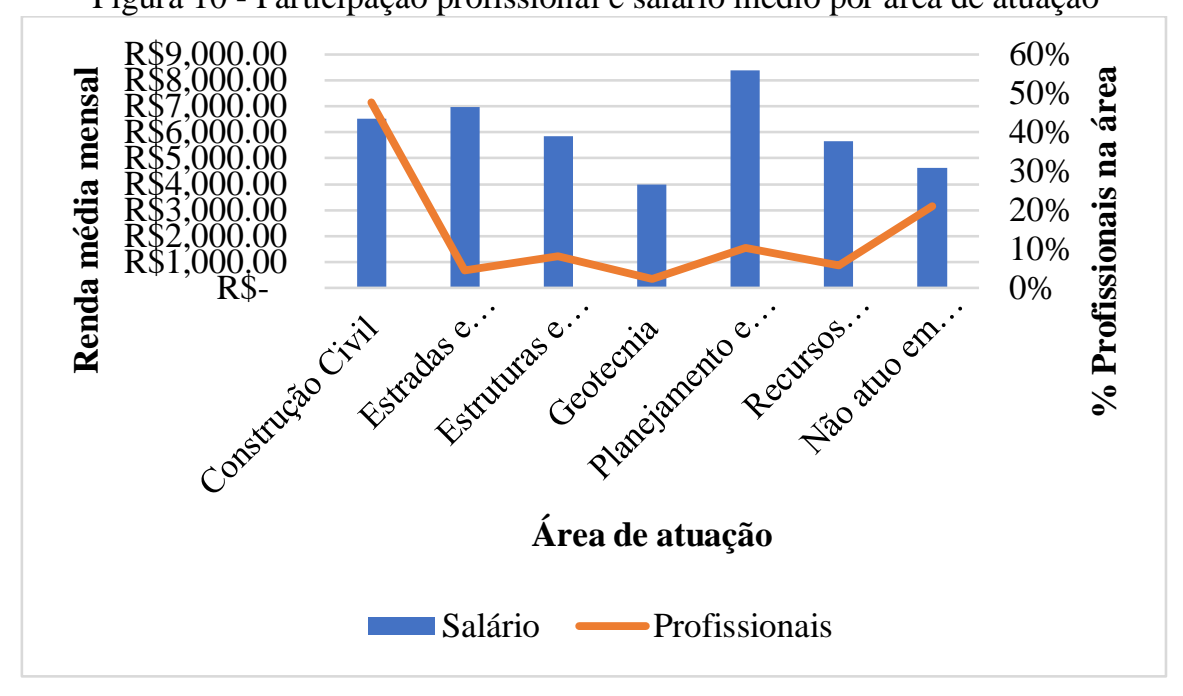

Fonte: Os autores (2020)

\section{Outra área de atuação}

Um dado que apresenta um comportamento ascendente, a cada nova turma formada, é o percentual de profissionais que não atuam em Engenharia Civil. O número é de $6 \%$ para aqueles formados em 2009 e 2010, passando para $7 \%$ nos anos de 2011 a 2014, subindo para $23 \%$ entre aqueles das turmas de 2015 e 2016 e, finalmente chegando a pouco mais de $1 / 3$ dos alunos graduados entre os anos de 2017 e 2018.

Os entrevistados distribuem-se em algumas áreas correlatas ao curso de Engenharia Civil, a exemplo de Engenharia de Petróleo e Engenharia Elétrica, e outras nem tanto, como Ciências dos Materiais, Administração Pública, Administração de Empresas, Medicina, Música, Finanças, Comércio e a carreira militar.

Quando perguntados, a respeito dos fatores que os influenciaram a mudar de área, o fator mais citado foi o "mercado da construção civil em declínio", mencionado em $22 \%$ das respostas coletadas. Pessoas com "interesse em outras áreas", bem como aqueles que tiveram "expectativas desencontradas com o curso", tiveram 18\% das respostas dadas. Um fator também significativo foi o de "mudanças de prioridades na vida", com $14 \%$ de citações, e "perseguir um sonho", com 11\% de frequência na seleção das respostas. Outros fatores como o "financeiro" (1\%), a "decepção com o curso" (4\%), a "busca por novos desafios" (8\%) e uma "rotina de trabalho estressante" ( $2 \%)$ estão entre os motivos que fizeram os egressos optarem por uma mudança na sua carreira. 


\title{
4 CONSIDERAÇÕES FINAIS
}

A partir das informações coletadas e do tratamento dos dados obtidos com esta pesquisa, percebe-se uma configuração preocupante de um cenário para os egressos, formados entre os anos de 2009 e 2018, no curso de Engenharia Civil da UFPB. Resultados como a alta taxa de desemprego, insatisfação profissional, mudança de área de atuação, média salarial abaixo do piso estabelecido para a categoria e o sentimento de despreparo quando concluída a graduação, questionam a eficácia e trazem à tona a discussão a respeito da forma como é estabelecida a formação do(a) profissional da Engenharia Civil atualmente.

Como sugestão, espera-se que este trabalho sirva de suporte a discussões a respeito de futuras revisões que possam atualizar o Plano Político Pedagógico do curso, vigente desde 2006, em função das novas DCN's e a necessidade de adequação às novas metodologias de ensino ativas bem como das exigências requeridas pelo mercado de trabalho.

\section{REFERÊNCIAS}

ALBERTE, E. P. V.; CARNEIRO, A. P.; CARVALHO, E. L. D. O. Impacto do perfil e experiência do egresso no delineamento de sua carreira como engenheiro. In: Congresso Brasileiro de Educação em Engenharia, 2018, Salvador. Anais. Salvador, 2018.

GIL, A. C. Métodos e técnicas de pesquisa social. 6. ed. São Paulo: Atlas, 2008.

LIMA, L. A.; ANDRIOLA W. B. Acompanhamento de egressos: subsídios para a avaliação de Instituições de Ensino Superior (IES). Avaliação, v. 23, n. 1, p. 104-125, mar. 2018.

MINISTÉRIO DA EDUCAÇÃO, CONSELHO NACIONAL DA EDUCAÇÃO. Consulta Pública. Diretrizes Curriculares Nacionais do Curso de Graduação em Engenharia, Abril 2019.

\section{Analysis of the profile of students graduated from the Civil Engineering course at the Federal University of Paraíba between 2009 and 2018}

\begin{abstract}
The Civil Engineering course at the Federal University of Paraíba graduated, in the last 10 years, more than 650 students. This article aims to analyze the profile of these professionals with a survey of their socioeconomic characteristics such as: education, income, sex, situation and professional insertion. The data were collected through the application of an online form. The participants were classified based on their responses and grouped according to their common characteristics. The results show a configuration of a worrying scenario for Civil Engineers graduated in recent years, mainly in issues such as insertion and job satisfaction.
\end{abstract}

Keywords: Evaluation. Graduates. Employment. Civil Engeneering. 